\title{
Low cost and high strength paste filling material with solid waste
}

\author{
Aixiang Wu University of Science and Technology Beijing, China \\ Wentao Lan University of Science and Technology Beijing, China \\ Yiming Wang University of Science and Technology Beijing, China \\ Zijun Li Guizhou CHANHEN Ltd, China
}

Jiacai Wang Guizhou CHANHEN Ltd, China

Jianqiu Li Guizhou CHANHEN Ltd, China

\begin{abstract}
Portland cement is the traditional filling materials used in China and features high cost, long maintenance cycle of filling body, and complicated process flow due to the use of thickening equipment and the addition of coarse aggregates to prepare paste slurry in complex production process (Yang et al., 2014). In order to solve those technical issues, the solid waste preparation of quick-setting materials and the semi-industrial test of filling mining technology were carried out in Guizhou ChanHen. The test used solid waste and additives as the main raw materials and is simple in the preparation process of slurry. The prepared paste does not become layered, segregated or blended and instead has excellent performance that is suitable for long distance pipeline transportation. The test also improved the strength of the filling body and made its strength range adjustable as well. For instance, the compressive strength of samples maintained for 3 days can reach $6 \sim 9$ MPa due to the excellent durability and resistance to weathering carbonization and harsh environment. Most importantly, the cost of the filling material is reduced, only 1/20 of that of the cement-based filling technology (Du et al., 2012). The test shows that great economic and social benefits could be produced if large-scale production could take place in China.
\end{abstract}

\section{Introduction}

Phosphorus gypsum is a discharged solid waste from the production of phosphate fertilizer and phosphorus acid, with one ton of phosphoric acid usually discharging 4.5 to 5 tons of phosphorus gypsum. Phosphorus gypsum includes a vast amount of dehydrate phosphorus gypsum $\left(\mathrm{CaSO}_{4} \cdot 2 \mathrm{H}_{2} \mathrm{O}\right)$, hemihydrate phosphorus gypsum $\left(\mathrm{CaSO}_{4} \cdot 1 / 2 \mathrm{H}_{2} \mathrm{O}\right)$, and a small amount of phosphoric acid, silicon, magnesium, iron, aluminium and organic impurities and so on.

The utilization rate of phosphorus gypsum is rather low, with an average of $4.5 \%$ worldwide (compared with its total amount of $12.6 \mathrm{Mt}$ ). However, in developed countries, such as Japan, Korea and Germany, the utilization rate is much higher. For instance, the effective utilization rate in Japan reaches over $90 \%$, with about $75 \%$ used to produce gypsum powder and gypsum board. In comparison, the utilization rate in less developed countries is elative lower as phosphorus gypsum mainly get discarded. Traditionally as an agriculture country, China has a huge demand for phosphate fertilizers. Phosphorus gypsum as the by- 
product of phosphorus chemical grows from 11 million tons in 2000 to 40 million tons in 2008. Since 2010, the production output increased to 4070 million tons every year, and by 2011, China had accumulated above 300 million tons of phosphorus gypsum. Nevertheless, the comprehensive utilization rate is only $10 \%$ and the annual utilization amount is only $4 \sim 5$ million tons. Furthermore, issues such as the deposition of phosphorus gypsum and impurities of tailings also resulted in huge economic output and severe environmental pollution. Using phosphorus gypsum for underground filling and goaf governance is currently the most effective way to increase the utilization of phosphorus gypsum. However, with the use of cement as the cementing material and phosphorus gypsum as the inert material, traditional filling features high cost and low consolidation strength. Although great progress has been achieved in the use of phosphorus gypsum for underground filling, the majority of the research is still based on its use as inert makings.

From A different perspective, the present research aims to use hemihydrate phosphorus gypsum as the cementing material due to its particular cementing properties so as to reduce filling cost and avoid the deposition of flotation tailings. This experiment used hemihydrate phosphorus gypsum as the main material and adopted both the orthogonal and uniform experimental design to improve the formula. The research also calculated the optimal ratio of accelerated material in phosphorus gypsum paste, analyzed the main factors influencing cementing properties, and concluded influences of various factors on the hydration process of phosphorus gypsum paste accelerated material.

\section{Experimental}

\subsection{Raw materials}

In this experiment, the phosphorus gypsum samples were taken from the press workshop of Guizhou ChanHen Chemical Limited Corporation, and the phosphate tailings were taken from the slag disposal pit in Guizhou ChanHen enterprise. Both the phosphorus gypsum and tailing samples were studied using X-Ray Fluorescence Spectrometer, and their chemical compositions are presented in Table 1 below.

Table 1 The chemical compositions of phosphorus gypsum and tailing

\begin{tabular}{cccccccccc}
\hline Raw Material & $\mathrm{CaO}$ & $\mathrm{Al}_{2} \mathrm{O}_{3}$ & $\mathrm{SiO}_{2}$ & $\mathrm{P}_{2} \mathrm{O}_{5}$ & $\mathrm{MgO}$ & $\mathrm{Fe}_{2} \mathrm{O}_{3}$ & $\mathrm{SO}_{3}$ & $\mathrm{SrO}$ & loss \\
\hline $\begin{array}{c}\text { Hemihydrate } \\
\begin{array}{c}\text { Phosphogypsum } \\
\text { Tailing }\end{array}\end{array}$ & 37.86 & 0.46 & 4.20 & 1.37 & 0.28 & 0.45 & 44.82 & 0.36 & 0.20 \\
\hline
\end{tabular}

Hemihydrate phosphorus gypsum is mainly composed of $\mathrm{CaO}$ and $\mathrm{SO}_{3}$, resulting in the cementing properties. In the chemical composition of tailings, the percentages of $\mathrm{CaO}$ and $\mathrm{MgO}$ are relatively higher, reaching 34.44 and $17.81 \%$ respectively. It shows that the characteristics of phosphorite tailings in ChanHen accord with those of dolomite and can be used as desirable inert materials with less harmful compositions like $\mathrm{P}_{2} \mathrm{O}_{5}, \mathrm{As}_{2} \mathrm{O}_{3}$, $\mathrm{SO}_{3}$ and so on. Therefore, the samples used in the research can be used as underground filling materials.
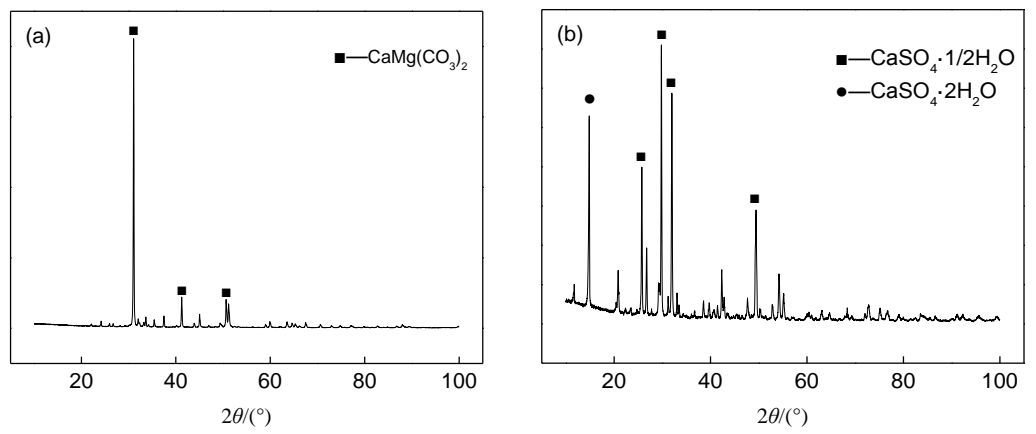
Figure 1 The X-Ray Diffract (XRD) analysis result of tailing(a) and hemihydrate phosphorus gypsum (b)

As Figure 1 shows, the main structure of phosphate tailing is dolomite $\left(\mathrm{CaMg}\left(\mathrm{CO}_{3}\right)_{2}\right)$ whose chemical composition is $30.4 \% \mathrm{CaO}$ and $21.7 \% \mathrm{MgO}$ and the loss on ignition maintains at 44.5 to $47.0 \%$. In comparison, the mineral components of hemihydrate phosphorus gypsum includes semi-hydrated gypsum and less dihydrate gypsum.

\subsection{Experiment design}

This experiment uses orthogonal design method and orthogonal table L9 $\left(3^{3}\right)$ with three four factors and three levels. The blank in the fourth column of orthogonal table is reserved for estimating variance. Three factors are (A) the mixing amount of cement, (B) the mixing amount of tailings, and (C) mass fraction respectively. The specific values of every factor are in Table 2 .

Table 2 Factors and levels of orthogonal design (\%) $L 9\left(3^{3}\right)$

\begin{tabular}{cccc}
\hline \multirow{2}{*}{ Level } & \multicolumn{3}{c}{ Factors Value } \\
\cline { 2 - 4 } & A & B & C \\
\hline 1 & 0.5 & 0 & $65 \%$ \\
2 & $1.0 \%$ & $20 \%$ & $67 \%$ \\
3 & $1.5 \%$ & $40 \%$ & $69 \%$ \\
\hline
\end{tabular}

\section{$3 \quad$ Results and discussion}

\subsection{Strength result}

The samples of phosphorus gypsum cementing materials were kept in three curing boxes with standard constant temperature and humidity and maintained for 3, 7 and 28 days respectively. The uniaxial compressive strength was then tested through compressive strength tester and the results are shown in Table 3. The optimal $3 \mathrm{~d}$ strength is found in No.7 experiment and is suitable for the matching of the paste accelerated material. The corresponding matching is $\mathrm{A}_{3} \mathrm{~B}_{1} \mathrm{C}_{3}$ (1.5\% cement, $0 \%$ tailings and $69 \%$ mass fraction), and the uniaxial compressive strengths of the samples maintained for 7 and 28 days are 5.5 and $5.4 \mathrm{MPa}$ respectively, meeting the requirements of general mining method, and the slump is up to $26 \mathrm{~cm}$. (Generally, when the slump is over $25 \mathrm{~cm}$, the paste has favorable liquidity)

Table 3 Results of orthogonal design

\begin{tabular}{|c|c|c|c|c|c|c|c|}
\hline Experiment No. & $\begin{array}{c}\text { A } \\
/(\%)\end{array}$ & $\begin{array}{c}\text { B } \\
/(\%)\end{array}$ & $\begin{array}{c}\mathrm{C} \\
/(\%)\end{array}$ & $\begin{array}{c}R_{3 \mathrm{~d}} \\
/(\mathrm{MPa})\end{array}$ & $\begin{array}{c}R_{7 \mathrm{~d}} \\
/(\mathrm{MPa})\end{array}$ & $\begin{array}{c}R_{28 \mathrm{~d}} \\
/(\mathrm{MPa})\end{array}$ & $\begin{array}{l}\text { Slump } \\
/(\mathrm{cm})\end{array}$ \\
\hline 1 & 0.5 & 0 & 65 & 0.6 & 3.7 & 5.4 & 28.0 \\
\hline 2 & 0.5 & 20 & 67 & 1.5 & 5.2 & 6.7 & 29.0 \\
\hline 3 & 0.5 & 40 & 69 & 1.3 & 4.4 & 3.8 & 29.0 \\
\hline 4 & 1.0 & 0 & 67 & 1.6 & 2.4 & 4.3 & 28.0 \\
\hline 5 & 1.0 & 20 & 69 & 3.4 & 5.4 & 8.1 & 29.0 \\
\hline 6 & 1.0 & 40 & 65 & 1.3 & 1.8 & 6.4 & 29.5 \\
\hline 7 & 1.5 & 0 & 69 & 5.4 & 5.5 & 6.1 & 26.0 \\
\hline 8 & 1.5 & 20 & 65 & 3.1 & 2.9 & 4.2 & 29.5 \\
\hline 9 & 1.5 & 40 & 67 & 2.8 & 3.1 & 4.1 & 29.4 \\
\hline
\end{tabular}




\subsection{Discussion}

\subsubsection{Range analysis}

According to the range analysis of the compression strength of new phosphorus gypsum cementing material maintained in different periods of 3, 7 and 28 days, the influence order of different factor can be analyzed and the optimal ratio formula of compound admixture can be calculated (see Table 4).

Table 4 Results of range analysis

\begin{tabular}{cccccc}
\hline Name & Factors & A & B & C & Effects \\
\hline & $\mathrm{k}_{1}$ & 1.14 & 2.77 & 1.67 & \\
& $\mathrm{k}_{2}$ & 2.09 & 2.68 & 1.97 & \\
$\mathrm{R} 3 \mathrm{~d} /(\mathrm{MPa})$ & $\mathrm{k}_{3}$ & 3.99 & 1.77 & 3.58 & $\mathrm{~A}>\mathrm{C}>\mathrm{B}$ \\
& Range & 2.85 & 1.00 & 1.91 & \\
& optimal level & $\mathrm{A}_{3}$ & $\mathrm{~B}_{1}$ & $\mathrm{C}_{3}$ & \\
& $\mathrm{k}_{1}$ & 4.43 & 3.91 & 2.81 & \\
& $\mathrm{k}_{2}$ & 3.21 & 4.50 & 3.59 & \\
$\mathrm{R} 7 \mathrm{~d} /(\mathrm{MPa})$ & $\mathrm{k}_{3}$ & 3.86 & 3.09 & 5.09 & $\mathrm{C}>\mathrm{B}>\mathrm{A}$ \\
& Range & 1.22 & 1.41 & 2.28 & \\
& optimal level & $\mathrm{A}_{1}$ & $\mathrm{~B}_{2}$ & $\mathrm{C}_{3}$ & \\
& $\mathrm{k}_{1}$ & 5.30 & 5.00 & 5.32 & \\
& $\mathrm{k}_{2}$ & 6.25 & 6.36 & 5.02 & \\
$\mathrm{R} 28 \mathrm{~d} /(\mathrm{MPa})$ & $\mathrm{k}_{3}$ & 4.56 & 4.75 & 5.77 & $\mathrm{~A}>\mathrm{B}>\mathrm{C}$ \\
& Range & 1.70 & 1.61 & 0.75 & \\
& optimal level & $\mathrm{A}_{2}$ & $\mathrm{~B}_{2}$ & $\mathrm{C}_{3}$ & \\
\hline
\end{tabular}

$K_{i}=$ the intended factor $(A, B$ or $C)$, sum of the average values of the three repetitions for level $i=1,2,3$;

$K_{i}=$ the intended factor $(A, B, C$,$) , average of the average values of the three repetitions for level i=1,2,3$;

$R=K m a x-K m i n ;$ larger $R$ value indicating more significant effects.

\subsubsection{Variance analysis}

Variance analysis identifies and analyzes the reasons for the differences of experimental results at different factor levels. The variance analysis of the strength of the samples maintained for 3,7 , and 28 days are shown in Table 5.

Table 5 Results of variance analysis

\begin{tabular}{cccccccc}
\hline Age & Variables & $\begin{array}{c}\text { Sum } \\
\text { squares }\end{array}$ & $\begin{array}{c}\text { Deg. of } \\
\text { freedom }\end{array}$ & $\begin{array}{c}\text { Mean } \\
\text { square }\end{array}$ & F-value & P-value & Effects \\
\hline \multirow{3}{*}{ 3d } & A & 12.76 & 2 & 6.38 & 8.53 & 0.10 & \\
& B & 1.70 & 2 & 0.85 & 1.13 & 0.47 & $\mathrm{~A}>\mathrm{C}>\mathrm{B}$ \\
& $\mathrm{C}$ & 6.50 & 2 & 3.25 & 4.34 & 0.19 & \\
$7 \mathrm{~d}$ & $\mathrm{~A}$ & 2.28 & 2 & 1.14 & 1.45 & 0.41 & \\
& $\mathrm{~B}$ & 2.95 & 2 & 1.47 & 1.87 & 0.35 & $\mathrm{C}>\mathrm{B}>\mathrm{A}$ \\
& $\mathrm{C}$ & 8.23 & 2 & 4.11 & 5.22 & 0.16 & \\
\multirow{2}{*}{ 28d } & $\mathrm{A}$ & 4.36 & 2 & 2.18 & 0.58 & 0.63 & $\mathrm{~A}>\mathrm{B}>\mathrm{C}$ \\
& $\mathrm{B}$ & 4.22 & 2 & 2.11 & 0.56 & 0.64 & \\
\hline
\end{tabular}

The results of variation analysis are in good agreement with that of the range analysis. It is found that the optimal experiment scheme combination of $3 \mathrm{~d}$ is $\mathrm{A}_{3} \mathrm{~B}_{1} \mathrm{C}_{3}$ (1.5\% chemical addition agent, $0 \%$ tailing, and $69 \%$ 
density); The optimal experiment scheme combination of $7 \mathrm{~d}$ is $\mathrm{A}_{1} \mathrm{~B}_{2} \mathrm{C}_{3}$ (0.5\% chemical addition agent, $20 \%$ tailing, and $67 \%$ density); The optimal experiment scheme combination of $28 \mathrm{~d}$ is $\mathrm{A}_{3} \mathrm{~B}_{1} \mathrm{C}_{3}$ (1\% chemical addition agent, 20\% tailing, and 69\% density); Based on the Data Processing Station (DPS) and the test data, the equations of uniaxial compressive strength for three curing periods were derived as: $R_{3 d}=-1903+706.7 \times A$ $+194 \times B+3788 \times C-1633 \times A B-241.7 \times B C-33.3 \times B^{2}-2750 \times C^{2}$. The correlation coefficient $R=0.99 ; R_{7 d}$ $=933.7+1.98 \times B-29.2 \times C-0.24 \times A C-0.03 \times B C+6.08 \times B^{2}+0.22 \times C^{2}$. The correlation coefficient $R=0.99$; $R_{28 d}=1505.1+3.61 \times B-46.3 \times C-0.06 \times A C-0.05 \times B C-1.07 A^{2}+0.35 \times C^{2}$. The correlation coefficient $\mathrm{R}=0.99$.

\subsection{Microstructure of hydrating products}

In the experiments, the mechanism of the new paste filling material were discussed by analyzing the hydrate and microstructure by SEM and XRD in the sample $A_{3} B_{1} C_{3}, A_{1} B_{2} C_{3}$, and $A_{2} B_{2} C_{3}$.

\subsubsection{SEM analysis}

After 28 days' paste curing, the samples $A_{3} B_{1} C_{3}, A_{1} B_{2} C_{3}, A_{2} B_{2} C_{3}$ were examined using scanning electron microscopy (SEM) and the observations are shown in Figure 2.

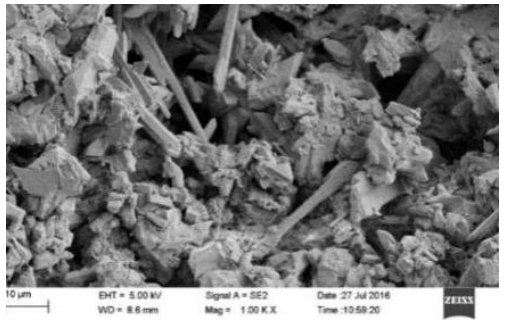

(a)

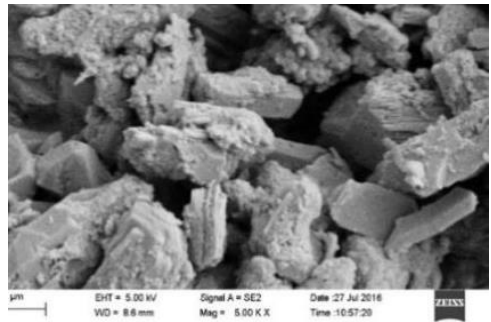

(b)

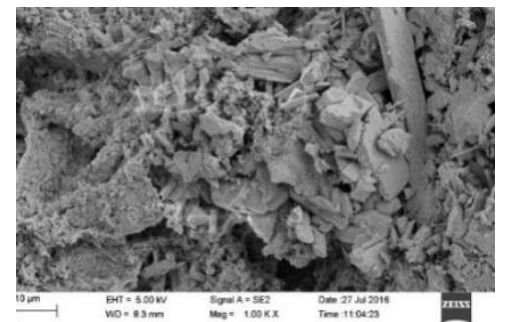

(c)

Figure 2 SEM images; (a) $A_{1} B_{2} C_{3}$; (b) $A_{3} B_{1} C_{3}$; (c) $A_{2} B_{2} C_{3}$

Figures show $\mathrm{CaSO}_{4} \cdot 2 \mathrm{H}_{2} \mathrm{O}$ as the main hydration product from all three kinds of matchings and the hydration reaction also thickens and widens the gypsum crystals. The size of dihydrate gypsum crystals with closely connected to each other is $0.5 \times 20^{2} \times 4 \mu \mathrm{m}$. Meanwhile, the spherical material gets attached onto the surface of gypsum crystals. In $A_{1} B_{2} C_{3}$ and $A_{2} B_{2} C_{3}$, the particle tailings filled among gypsum crystals and the structure of crystals was sparse. However, in $A_{3} B_{1} C_{3}$, particle tailings were not found and the crystals structure was dense, revealing the reasons for its high strength.

\subsubsection{XRD analysis}

Through XRD analysis, samples were examined in terms of the changes of hydration outcome composition. The observations are shown in Figure 3.

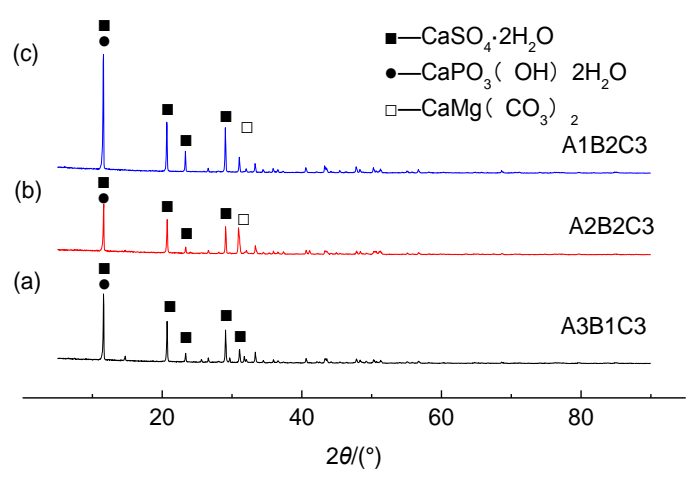

Figure 3 XRD patterns of hydration products of $4 \#$ and 7\# sample at 28 days

It is shown that the main hydration product of filling materials is $\mathrm{CaSO}_{4} \cdot 2 \mathrm{H}_{2} \mathrm{O}$, which shows the good 
agreement between the actual hydration process and the hydration theory of semi-hydrated gypsum. The hydration reaction equation can be described as:

$$
\mathrm{CaSO}_{4} \cdot 0.5 \mathrm{H}_{2} \mathrm{O}+1.5 \mathrm{H}_{2} \mathrm{O} \rightarrow \mathrm{CaSO}_{4} \cdot 2 \mathrm{H}_{2} \mathrm{O}+\mathrm{Q}
$$

With the formation of dihydrate gypsum, $\mathrm{CaPO}_{3}(\mathrm{OH})_{2} \mathrm{H}_{2} \mathrm{O}$ appeared and little $\mathrm{CaPO}_{3}(\mathrm{OH})_{2} \mathrm{H}_{2} \mathrm{O}$ gets generated, leading to the solidifying effects of the selected modifiers. Harmful substances as well as the floatation pollution could also be reduced with the use of new materials. Although the research mainly focuses on the environmental aspects, no evidence shows that other potentially harmful substances may be present and no other components have been found except for $\mathrm{CaPO}_{3}(\mathrm{OH})_{2} \mathrm{H}_{2} \mathrm{O}, \mathrm{CaSO}_{4} \cdot 2 \mathrm{H}_{2} \mathrm{O}$ and $\mathrm{CaMg}\left(\mathrm{CO}_{3}\right)_{2}$.

\section{Conclusions}

Firstly, through the experiment of semi-hydrate phosphogypsum, it is concluded that with cementing properties, semi-hydrate phosphogypsum can replace cement as a cementing material. Meanwhile, with the use of phosphate flotation tailings as inert materials, a new rapid-hardening filling material of phosphorgypsum is initially made with high strength. The uniaxial compressive strength of the samples maintained for 3 days is above $6^{\sim} 9 \mathrm{MPa}$, and the long-term uniaxial compressive strength exceeds $5 \mathrm{MPa}$, which meets the mining requirements in filling strength.

Secondly, through orthogonal experiment analysis, it is found that the main factor influencing the early and later strength of fillings is the mixing amount of cement, and the factor influencing the middle strength of filling is the mixing amount of tailings. Besides, for 3 days' filling strength, the mixing amount of cement is the main influencing factor. According to range analysis and variance analysis, the optimum strength for samples maintained for 3 days is the $A_{3} B_{1} C_{3}$ matching.

Last but not least, solid wastes like phosphogypsum and tailings are the main raw materials (over $98 \%$ ) in the rapid-hardening filling of phosphor-gypsum. Meanwhile, due to the low cost of cement, it is conclude that the new cementing materials can not only improve the strength of filling body and reduce the cost of mine filling, but also solve the deposition problem of solid wastes in phosphor-chemical enterprise, hence generating significant economic and social benefits.

\section{References}

Du, J.Q., Gao, Q., Nan, S.Q. and Dong, L. 2012, 'Develop on a new cementing material of full tailings backfilling', Metal Mine, no. 5, pp. 152.

Yang, Z.Q., Gao, Q., Wang, Y.Q., Ni, W. and Chen, D.X. 2014, 'Experimental study on new filling cementing material using water-hardening nickel slag tailings of Jinchuan Mine', Chinese Journal of Geotechnical Engineering, vol. 36, no. 8, pp. 1498-1506. 